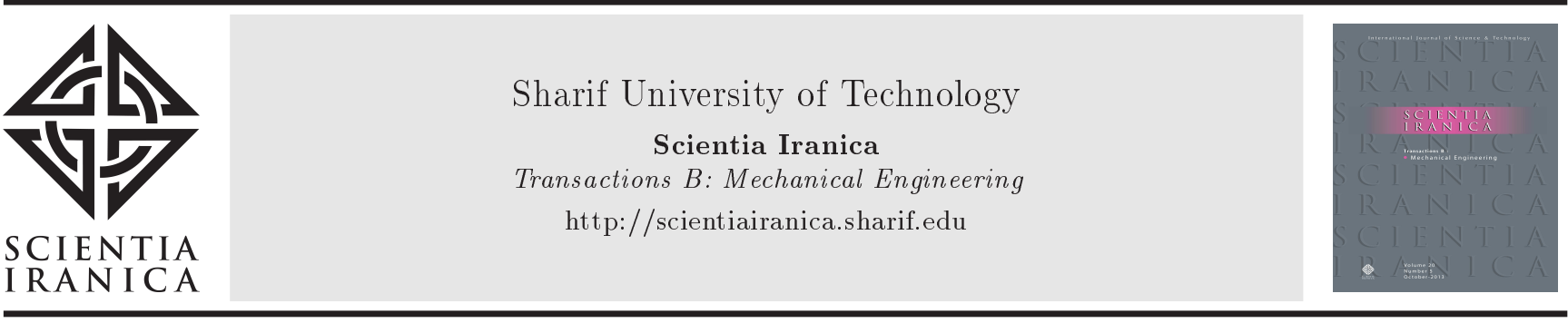

\title{
Numerical study of jet impingement subcooled boiling on superheated surfaces
}

\author{
K. Esmailpour ${ }^{\mathrm{a}, *}$, A. Azizi ${ }^{\mathrm{b}}$, and S.M. Hosseinalipour ${ }^{\mathrm{b}}$ \\ a. Department of Mechanical Engineering, Islamic Azad University, Damavand Branch, Damavand, P. O. Box 16765-163, Iran. \\ b. Department of Mechanical Engineering, Iran University of Science and Technology, Tehran, Iran. \\ Received 6 March 2017; received in revised form 5 March 2018; accepted 7 July 2018
}

\author{
KEYWORDS \\ Jet impingement; \\ Subcooled boiling; \\ Eulerian multiphase \\ model; \\ Mass transfer \\ enhancement; \\ Interfacial terms.
}

\begin{abstract}
Cooling techniques for superheated surfaces by jet impingement, taking advantage of phase change phenomenon, i.e., boiling heat transfer, have been proven to be an efficient method because of their high rate of heat transfer. Furthermore, at a specified heat transfer coefficient, the flow required for cooling purposes can decrease by two orders of magnitude in comparison with the free-wall parallel flow, which is significant in terms of energy and water sustainability issues in various industries. This research is mainly concerned with numerical simulation of hydrodynamics and heat transfer phenomena regarding phase-change jet impingement on nucleate boiling region. Rensselaer Polytechnic Institute wall boiling model, based on Eulerian multiphase model, and RNG $k-\varepsilon$ turbulence model were employed. Each interfacial term was considered and selected based on proximity to real physical phenomena. The selected model in this research was validated by a previously performed confined jet impingement subcooled boiling experiment (dielectric fluid-PF 5060). Minimum error of $4 \%$ and maximum error of $15 \%$ were reached at stagnation point. In the parametric study, the effect of jet Reynolds number based on nozzle hydraulic diameter at Re values of 2500 to 10000 and the effect of standoff distance of jet nozzle from target surface at $H / D$ values of 2,4 , and 6 were investigated.
\end{abstract}

(C) 2019 Sharif University of Technology. All rights reserved.

\section{Introduction}

Jet impingement heat transfer with phase change is considered as one of the most efficient cooling methods for thermal management in various industries. Jet impingement boiling heat transfer has a number of applications in heat treatment of materials and smart surfaces, cooling of electronic modules, emergency cooling of safety systems, to name a few [1]. The main four regimes in the jet impingement boiling curve are

\footnotetext{
*. Corresponding author. Tel.: +9821 77240540-50 (Ex: 2929); Fax: +9821 7r240488

E-mail addresses: Esmailpour@damavandiau.ac.ir (K. Esmailpour); Aazizi1@binghamton.edu (A. Azizi); Alipour@iust.ac.ir (S.M. Hosseinalipour)
}

forced convection (single-phase heat transfer), nucleate boiling, transition boiling (shoulder of flux), and film boiling. This study is mostly focused on nucleate boiling, since a vast majority of the mentioned applications operate in this region [2]. Transient conduction by the displacement of hot liquid bulk into thermal boundary layer through cyclic bubble nucleation, growth, and departure; vapor embryo formation; and enhanced convection are the primary heat transfer mechanisms in the nucleate boiling process [3]. Turbulence characteristics, which appear due to local jet hydrodynamics, are influenced by the vaporization process as well $[4,5]$. Karwa. carried out experimental studies on water jet impingement of hot steel plates. Mechanistic or subscale modeling was implemented by multiphase flow visualization with high speed imaging, and fastresponse thermocouples were embedded within the 
surface of stainless steel AISI-type 314 cylinder with homogeneous initial temperature of 900 degrees Celsius. As bubble dynamics and nucleation sites played a crucial role in jet boiling heat transfer mechanism, the observations confirmed that removal of bubbles by forced convection penetrated by jet flow in the early stages of growth and rapid condensation of the bubble cells after ebullition of the hot surface would prevent the buildup of vapor near the wall, which was a significant outcome to further their analysis [6]. The analytical force balance approach employed by Klausner et al. demonstrated increase in shear, drag, and, consequently lift force as a result of increase in flow velocity. Degree of subcooling and heat flux have considerable effect on the decrease in bubble size, lifetime, and departure diameter. In the jet impingement boiling situation, bubble departure diameter is predicted in $\mathrm{O}(10) \mu \mathrm{m}$ and lifetime in $\mathrm{O}(0.1) \mathrm{ms}$. It has been stated in various studies that the current state-of-the-art high-speed imaging is not able to fully observe such small-scale and short-lived phenomena. For this reason, the numerical approach has also been used by many researchers in order to achieve higher accuracy in understanding the physics of phase-change jet impingement cooling $[7,8]$. In the steady-state measurements, a particular boiling condition can be sustained long enough in order to capture necessary details of bubble dynamics. Nevertheless, high thermal capacity of the superheated surface is a key function in slowing down time-dependent temperature variations regarding boiling phenomena in various regions. In addition, constant surface temperature is preferable to constant heat flux rate since the latter provides further instabilities in the nucleation process $[9,10]$. Many of the models developed for various parameters in boiling, such as interphase interaction terms, are based on pool or parallel flow boiling configurations aimed at nuclear engineering applications and only few limited investigations have been performed on subscale modeling of jet impingement boiling. Omar et al. developed a mechanistic model in order to predict bubble growth and degeneration, i.e., bubble departure diameter, considering jet velocity, surface superheat, and the degree of subcooling by a semi-empirical approach using non-linear regression analysis. Their model decreased inaccuracies caused by applying flow boiling formulations to the jet configuration. However, they emphasized that as the model was based on experimental data over a specific range for the parameters, it could be used at higher or lower ranges with the same confidence $[11,12]$. Shin et al. experimentally investigated single- and two-phase confined impingement jets with various Reynolds numbers and standoff distances. Dielectric fluid PF-5060 with the constant degree of subcooling of $25 \mathrm{~K}$ was used in this experiment. The target surface was Inconel-600 plate with $467 \mu \mathrm{m}$ thickness. Thermal boundary condition of the plate was for electrical resistive heating, which was monitored by $7 \mathrm{~K}$-type thermocouples for temperature measurements [13]. This experiment is employed in this paper in order to validate the proposed numerical simulation.

Narumanchi et al. simulated the nucleate boiling process by jet impingement through numerical methods by ANSYS Fluent, proposed in previous studies. Rensselaer Polytechnic Institute (RPI) Eulerian multiphase model was utilized in order to predict the dispersed flow condition resulting from boiling on the superheated surface and various models were employed in order to simulate interphase interaction terms such as interfacial area concentration, lift, turbulent dispersion force, bubble departure diameter, etc. In this numerical study, $20 \%$ deviation from experiment at stagnation point was considered to be an appropriate error in the configuration due to the complexity of the involved physics [14]. Abishek et al. recently conducted numerical research on jet impingement boiling based on RPI wall boiling model. According to their studies, RNG $k-\varepsilon$ model with enhanced wall treatment offers suitable accuracy compared to other RANS-based turbulence models. Furthermore, Unal's formulation with heat transfer controlled model for bubble departure diameter combined with Podowski's or Cole's model for bubble departure frequency had the highest precision in their simulation [15]. Shademan recently investigated flow, heat, and mass transfers of a jet issued from a circular nozzle, numerically [16]. They used a Eulerian-Eulerian two-phase flow model to study boiling phenomenon in impinging jet configuration. Comparison of their results with the experimental results confirmed the validity of their developed model for impinging jets. Qiu et al. provided a comprehensive review of jet impinging boiling [17]. Their article mainly focused on experimental studies, but the RPI model was also discussed briefly. Qiu et al. investigated a three-dimensional conjugation heat transfer problem involving water boiling process in the hot tube array configuration, experimentally and numerically [18]. They simulated water boiling by RPI model. They mainly focused on the empirical study and the effects of air and water flow rates were studied as key parameters for the flow and thermal characteristics.

As observed in the review of the literature, further analysis of the numerical simulation of jet impingement subcooled boiling and diverse parametric studies can play a key role in better understanding of the underlying physics of this configuration, as only few researches have been carried out in this area. Since the effects of jet Reynolds number and standoff distance from target surface are two of the most important parameters in jet impingement research, these criteria are investigated in this paper. In order to measure the precision of the 
results of the numerical framework, a case study based on experimental data is conducted.

\section{Geometry and computational domain}

The geometry in this study is considered for the confined jet with slot nozzle. As the computational domain is symmetric, only half of the geometry is considered in the simulations to decrease computational expenses. Gravity is taken into account, since it is an important parameter regarding the involved physics. No-slip condition is applied to the walls. Fluid characteristics varying with temperature and density gradients are modeled based on Boussinesq approximation. Thermophysical properties of the working fluid used in this study are available in Table 1.

Figure 1 displays the configuration of the parametric studies. Water is used as working fluid with 20 degrees Kelvin of subcooling. Nozzle diameter is $2 \mathrm{~mm}$. Target surface consists of two parts. The first part is a copper plate with the width of $6 \mathrm{~mm}$, thickness of $200 \mu \mathrm{m}$, and depth of $10 \mathrm{~mm}$ and the second part is two polycarbonate plates with the same size along the surface for insulation.

As mentioned earlier, the computational domain is non-uniform in this meshing in order to reach higher accuracy with minimum computational expense. Mesh independency tests based on the parameters with higher sensitivities, such as vapor volume fraction, are performed in each case to reach the optimum amount of cells. Approximately $100 \times 690$ cells are used for $H / D=4$ configuration as shown in Figure 2.

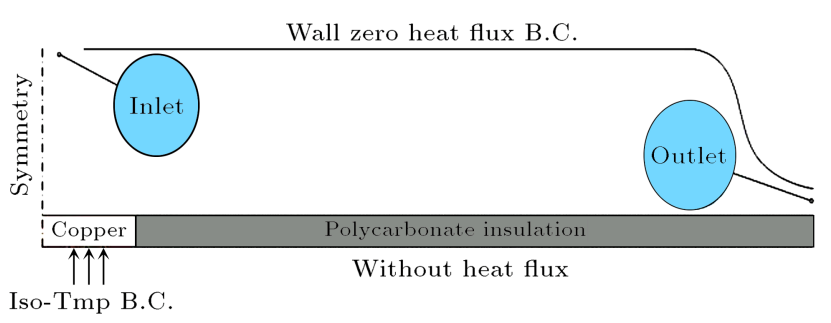

Figure 1. Schematic of the configuration considered for parametric studies.

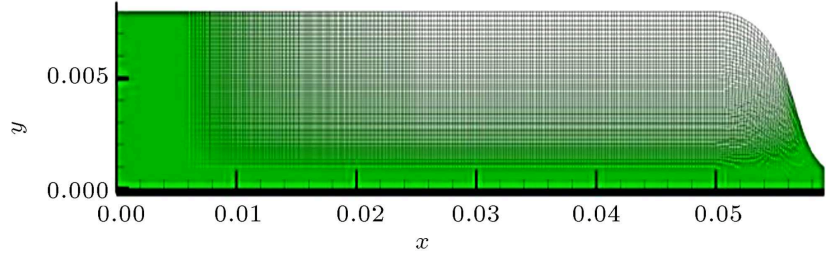

Figure 2. Meshing and computational domain of the configuration considered for parametric study with $H / D=4$.

$y^{+}$of the first cell of the liquid phase in the stagnation point is approximately 0.2 and it reaches the maximum of 1.6 along the plate. $y^{+}$of the vapor phase, based on the chosen thermal boundary condition, is less than 0.5 .

\section{Mathermatical formulation and modeling}

In this study, subcooled boiling is modeled by the Euler-Euler approach using finite volume method code developed in OpenFOAM v4.1. In the Euler-Euler approach, different phases are handled as interpenetrating continua. Phasic volume fraction is introduced in this context, which is considered as a continuous function of time and space. Wall boiling models such as that of Rensselar Polytechnic Institute are developed based on Eulerian model, which has the most complex formulations in this category. The Eulerian model solves " $n$ " number of conservation equations of mass, momentum, and energy for each phase. These governing equations are coupled via pressure and interphase interaction coefficients. These coefficients are treated with regard to the type of phases involved, i.e., liquid-gas dispersed flow due to boiling, in this study. The interfacial terms may be nonlinear; hence, convergence of these models can be slow. Furthermore, the accuracy of the model is directly affected by the closeness of these coefficients to the real physical phenomenon [19].

Kurul and Podowski stablished the RPI wall boiling model [20]. Based on their explanation as well as Figure 3, total wall heat flux consists of three components, namely convective heat flux, quenching

Table 1. Thermo-physical properties of the working fluid.

\begin{tabular}{ccccccccc}
\hline \multirow{2}{*}{ Property } & Units & $\begin{array}{c}\text { PF-5060 } \\
\text { liquid }\end{array}$ & $\begin{array}{c}\text { PF-5060 } \\
\text { vapor }\end{array}$ & $\begin{array}{c}\text { Water } \\
\text { liquid }\end{array}$ & $\begin{array}{c}\text { Water } \\
\text { vapor }\end{array}$ & $\begin{array}{c}\text { Inconel } \\
\mathbf{6 0 0}\end{array}$ & Copper & Polycarbonate \\
\hline$\rho$ & $\mathrm{kg} / \mathrm{m}^{3}$ & 1658.836 & 13.4 & 965.23 & 0.5976 & 8470 & 8978 & 1210 \\
$K$ & $\mathrm{~W} / \mathrm{m}-\mathrm{K}$ & 0.05658 & 0.02 & 0.675 & 0.02512 & 14.9 & 387.6 & 0.22 \\
$C_{P}$ & $\mathrm{~J} / \mathrm{kg}-\mathrm{K}$ & 1062.347 & 500 & 4205.54 & 2078.18 & 444 & 381.0 & 1250 \\
$\mu$ & $\mathrm{kg} / \mathrm{m} . \mathrm{s}$ & $5.65 \times 10^{-4}$ & $1.81 \times 10^{-5}$ & $3.156 \times 10^{-4}$ & $1.227 \times 10^{-4}$ & - & - & - \\
$T_{\text {sat }}$ & $\mathrm{K}$ & 329.15 & - & 373.15 & - & - & - & - \\
$\sigma$ & $\mathrm{N} / \mathrm{m}$ & 0.00827 & - & 0.059 & - & - & - & - \\
$L$ & $\mathrm{~J} / \mathrm{kg}$ & 97000 & - & 2257000 & - & - & - & - \\
\hline
\end{tabular}




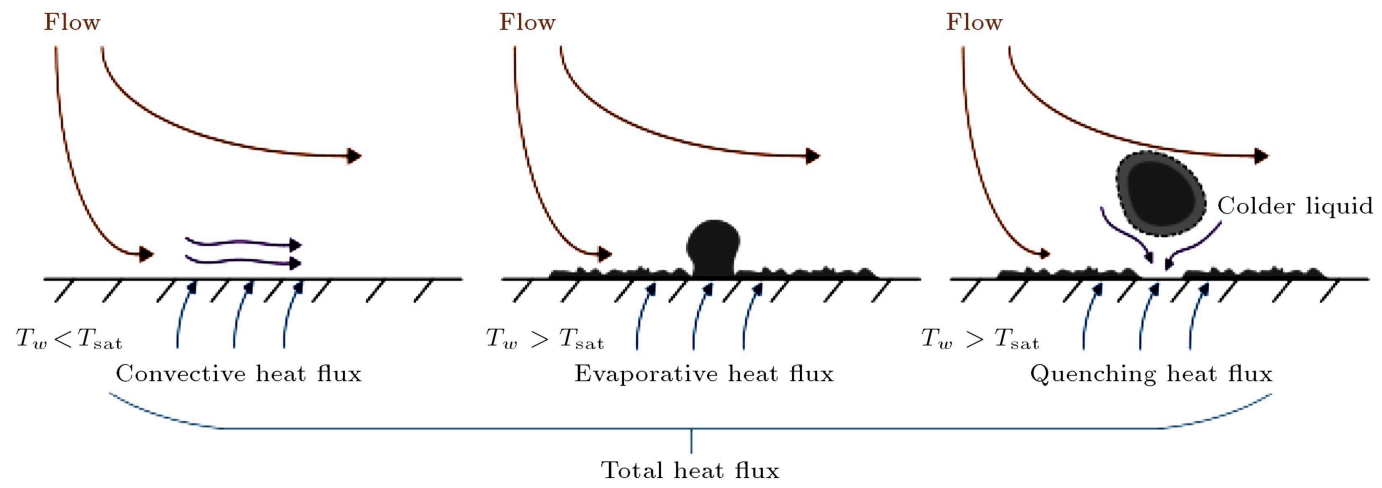

Figure 3. Schematic of RPI wall boiling model.

heat flux, and evaporative heat flux, with the following formulations:

$$
\dot{q}_{W}=\dot{q}_{C}+\dot{q}_{Q}+\dot{q}_{E} .
$$

Convective heat flux is expressed as follows:

$$
\dot{q}_{C}=h_{c}\left(T_{w}-T_{l}\right)\left(1-A_{b}\right) .
$$

In the above equation, $h_{c}$ indicates single-phase convective heat transfer coefficient, and $T_{w}$ and $T_{l}$ are wall and liquid temperatures. The value of $T_{l}$ is calculated based on fixed $y^{+}$of 250, proposed by Egorov and Menter [21]. Quenching heat flux refers to average heat transfer due to instant periodic displacement of cold liquid after detachment of bubble from the surface and it is calculated by Eq. (3):

$$
\begin{aligned}
& \dot{q}_{Q}=2 K_{l}\left(T_{w}-T_{l}\right) /\left(\pi \lambda_{l} T\right)^{0.5}, \\
& \lambda_{l}=\frac{K_{l}}{\rho_{l} C_{p l}},
\end{aligned}
$$

where $K_{l}, \lambda_{l}$, and $T$ are thermal conductivity, diffusivity, and periodic time (cyclic averaged), respectively.

Evaporative heat flux is represented by Eq. (5):

$$
\dot{q}_{E}=V_{d} N_{w} \rho_{v} f h_{f v}
$$

where $V_{d}$ is volume of bubble based on bubble departure diameter, $N_{w}$ is nucleation site density, $\rho_{v}$ is vapor density, $h_{f v}$ is latent heat for vaporization, and $f$ is bubble departure frequency.

Effective area or area of influence is the area occupied by bubbles across nucleation site. $K$ is an empirical constant, which has been modified by Del Valle and Kenning based on subcooled Jacob number [22]:

$$
\begin{aligned}
& A_{b}=\min \left(1, K \frac{N_{w} \pi D_{w}^{2}}{4}\right), \\
& K=4.8 e^{\left(-0.0125 J a_{\mathrm{sub}}\right)}, \\
& J a_{\mathrm{sub}}=\rho_{l} C_{p l} \Delta T_{\mathrm{sub}} / \rho_{v} h_{f v},
\end{aligned}
$$

where $\Delta T_{\text {sub }}$ is the difference between saturation temperature and liquid temperature.

Bubble departure frequency was calculated in the photographic study of Cole for pool boiling of distilled water in the near-critical heat flux region [23]:

$$
f=\frac{1}{T}=\left[4 g\left(\rho_{l}-\rho_{v}\right) / 3 \rho_{l} D_{w}\right]^{0.5} .
$$

The effects of wall heat flux, liquid subcooling, liquid velocity, and boiling cavity radius on the total bubble departure time have been investigated based on dwell time and growth time by Podowski et al. [24]. This parameter is commonly presented by a semi-empirical formulation based on wall superheat. Nucleation site density is greatly dependent on surface roughness in microscale. It has almost no effect on liquid temperature, slight influence on gas volume fraction, and dominant effect on wall superheat [25]:

$$
N_{w}=C^{n}\left(T_{w}-T_{\text {sat }}\right)^{n} .
$$

The empirical coefficients of Lemmert and Chawla with $n=1.805$ and $c=210$ are used in this study [26].

There are a number of formulations available for bubble departure diameter. Semi-empirical correlations of Unal based on mechanistic heat transfer controlled bubble model in the "forced-convection surface-boiling" or "partial nucleate boiling" regime seem to have high reliability in predictions compared to other bubble size detachment correlations such as the observations of Tolubinsky and Kostanchuk [27,28].

$$
\begin{aligned}
& D_{w}=2.4210^{-5} P^{0.709}\left(\frac{a}{b \sqrt{\varphi}}\right), \\
& a=\frac{\Delta T_{\mathrm{sup}}}{2 \rho_{g} H_{l v}} \sqrt{\frac{\rho_{s} C_{p s} K_{s}}{\pi}}, \\
& b=\left\{\begin{array}{l}
\frac{\Delta T_{\mathrm{sub}}}{2\left(1-\frac{\rho_{g}}{\rho_{l}}\right)} e^{\left(\frac{\Delta T_{\mathrm{sub}}}{3}-1\right)} \Delta T_{\mathrm{sub}} \leq 3 \\
\frac{\Delta T_{\mathrm{sub}}}{2\left(1-\frac{\rho_{g}}{\rho_{l}}\right)} \Delta T_{\mathrm{sub}}>3
\end{array}\right.
\end{aligned}
$$




$$
\varphi=\max \left(\left(\frac{U_{b}}{U_{0}}\right)^{0.47}, 1.0\right)
$$

Eqs. (11) refer to Unal's formulation, where $U_{b}$ is nearwall velocity and $\Delta T_{\text {sup }}$ is wall superheat.

This parameter is different from bubble departure diameter and it refers to average bubble diameter in bulk flow. Kurul and Podowski suggested a correlation by a user-defined function in the simulation [29]:

$$
d_{b}=\left\{\begin{array}{l}
d_{b}^{\max }+\theta \times \Delta T_{\mathrm{sub}} \\
\quad \text { if } 0 \leq \Delta T_{\mathrm{sub}} \leq \Delta T_{\mathrm{sub}}^{\max } \\
\max \left(d_{b}^{\min } \times \exp \left[\frac{\left(\Delta T_{\mathrm{sub}}-\Delta T_{\mathrm{sub}}^{\max }\right) \theta}{d_{b}^{\min }}\right], 10^{-5}\right) \\
\quad \text { if } \Delta T_{\mathrm{sub}} \geq \Delta T_{\mathrm{sub}}^{\max } \\
10^{-3} \\
\quad \text { if } \Delta T_{\mathrm{sub}} \leq 0
\end{array}\right\},
$$

where $d_{b}^{\min }=1.5 \times 10^{-4} \mathrm{~m}$ and $d_{b}^{\max }=10^{-3} \mathrm{~m}$ are constants in Eq. (12).

In the Eulerian multiphase formulation, field and constitutive equations of each phase are solved separately. However, since averaged fields of each phase are coupled together to some degree, the interaction terms appear in the equations by taking into account the dynamic and non-equilibrium states. Interfacial momentum, mass, and energy transfer are modeled in terms of interfacial transfer conditions and constitutive laws for interactions between phases.

There is a strong relation between interfacial transport terms of mass, momentum, and energy and interfacial area concentration. The interfacial area concentration, defined as interfacial area between two phases per unit mixture volume, is related to the structure of two-phase flow. The algebraic formulation of Habiki and Ishii for boiling flows is used [30]:

$$
A_{i}=\frac{6\left(1-\alpha_{p}\right) \min \left(\alpha_{p}, \alpha_{\text {pcrit }}\right)}{D_{w}\left(1-\min \left(\alpha_{p}, \alpha_{\text {pcrit }}\right)\right)} .
$$

The interfacial heat transfer coefficient is calculated according to the correlation of Ranz and Marshall for Nusselt number as follows [31]:

$$
\mathrm{Nu}_{q}=2+0.6 \operatorname{Re}_{p}^{1 / 2} \operatorname{Pr}_{q}^{1 / 3} .
$$

\subsection{Momentum transfer modeling}

Ishii model is employed for Drag coefficient, $C_{D}$, in bubbly flows, which is determined based on the minimum value between viscous region and distorted region [32]:

$$
C_{D}=\min \left(\frac{24}{\operatorname{Re}}\left(1+0.15 \operatorname{Re}^{0.75}\right), \frac{2}{3} \frac{D_{w}}{\left(\frac{\sigma}{g\left|\rho_{p}-\rho_{q}\right|}\right)^{\frac{1}{2}}}\right)
$$

The lift force as a result of interaction of the generated bubbles with shear layer is modeled by the formulation of Moraga et al. The lift coefficient in their model considers:

1. Aerodynamic lift resulting from interaction between bubbles and continuous phase;

2. Vorticity induced lift due to interaction between dispersed phase particles and vortices by bubble wake [33].

$$
C_{l}=\left\{\begin{array}{l}
0.0767 \\
\phi \leq 6000 \\
-\left(0.12-0.2 e^{-\frac{\phi}{3.6} \times 10^{-5}}\right) e^{\frac{\phi}{3} \times 10^{-7}} \\
6000<\phi<5 \times 10^{7} \\
-0.6353 \\
\phi \geq 5 \times 10^{7}
\end{array}\right\}
$$

where $\phi$ is the product of bubble Reynolds number, $\operatorname{Re}_{b}$, and vorticity Reynolds number, $\operatorname{Re}_{V}$.

Turbulent dispersion force results from chaotic liquid velocity fluctuations and acts as turbulent diffusion in turbulent dispersed flows. Burns et al. came up with a formulation from Favre averaging of the interfacial drag force [34]. The modified two-phase dispersed flow formulation is shown below:

$$
F_{q}^{\mathrm{disp}}=-F_{p}^{\mathrm{disp}}=-C_{q p} \frac{v_{t q}}{\sigma_{T D}}\left(\frac{1}{\alpha_{q}}+\frac{1}{\alpha_{p}}\right) \nabla \alpha_{q} .
$$

$C_{q p}$ is interphase exchange coefficient for the interfacial drag force, $v_{t q}$ is kinematic eddy viscosity of the dispersed phase, and $\sigma_{T D}$ is turbulent Prandtl number for volume fraction dispersion.

\subsection{Modeling of turbulence}

Prediction of turbulent flow in the impinging jets has some difficulties due to complex flow hydrodynamics in this configuration. Jet expansion angle, interaction between inlet flow from nozzle and static fluid in the surrounding, turbulence intensity increase in the direction of the jet axis, possible relaminarization around stagnation region, and possible transition from laminar to turbulent flow in the wall jet region are only some cases of the mentioned complexity [35].

Several investigations were pursued by researchers in the past decade into accurate modeling of heat transfer and fluid flow in the impinging jets [36]. RNG $k-\varepsilon$ RANS based turbulence model combined with enhanced wall treatment is employed in this research due to its high accuracy of predictions in addition to low computational expense. Necessary precautions for 
mesh size regarding $y$-plus limit based on the chosen wall treatment were observed.

The influence of dispersed phase on the turbulent flow can be considered by two source terms in the modified $k-\varepsilon$ equations modeled by Troshko and Hassan [37].

$$
\begin{aligned}
& \pi_{K_{m}}=C_{k e} \sum_{p=1}^{M} K_{p q}\left|\bar{U}_{p}-\bar{U}_{q}\right|^{2}, \\
& \pi_{\varepsilon_{m}}=C_{t d} \frac{1}{\tau_{p}} \pi_{K_{m}} .
\end{aligned}
$$

\section{Solution method}

Pressure and velocity coupling was achieved by a coupled algorithm in this simulation. Discretization of momentum, energy, turbulent kinetic energy, and turbulent dissipation rate is obtained by the Quadratic Upstream Interpolation for Convective Kinematics (QUICK) scheme. In addition, modified High-Resolution Interface Capturing (HRIC) is employed for volume fraction discretization. Convergence criterion for all parameters is defined by Eq. (20):

$$
\left|\frac{\varphi_{n+1}-\varphi_{n}}{\varphi_{n}}\right| \leq 10^{-6}
$$

\section{Validation of the numerical framework}

The numerical model in this research is validated by the experimental study of Shin et al. [13]. Jet Reynolds number based on hydraulic diameter is 1999 and nozzle standoff distance from target surface is $8 \mathrm{~mm}(H / D=$ 4). The configuration consists of an Inconel plate with the depth of $8 \mathrm{~mm}$ and width of $50 \mathrm{~mm}$, of which the first $10 \mathrm{~mm}$ is heated by resistive heating. Volumetric heat generation is employed in order to model thermal boundary conditions of this problem. Atmospheric condition is applied to pressure and PF-5060 liquid inlet temperature is $304.15 \mathrm{~K}$. Polycarbonate plates are used for insulation based on the schematic given in Figure 4.

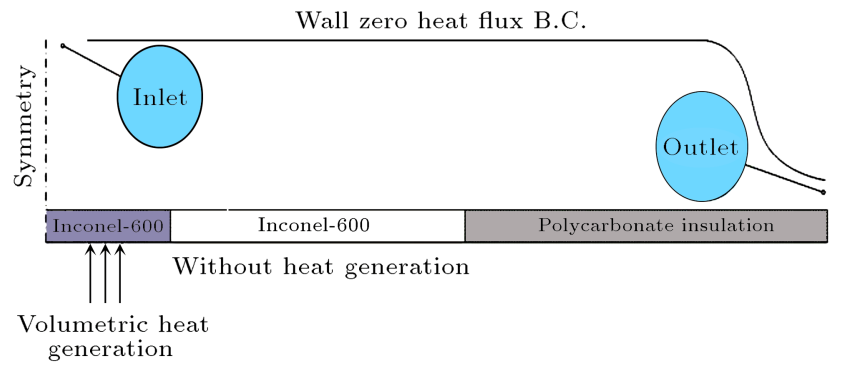

Figure 4. Schematic of the configuration considered for validation.
Non-uniform meshing is employed with higher concentration of computational cells in the areas with higher gradients, such as stagnation region. The rectangular cells are used in this mesh as shown in Figure 5.

\section{Result and discussion}

\subsection{Validation of the numerical framework}

Figure 6 presents a comparison between the boiling curves obtained in the present study and the experimental boiling result of Shin et al. [13]. The average total surface heat flux is calculated after convergence and plotted in terms of saturation temperature difference.

Minimum and maximum deviations of $4 \%$ and $15 \%$ are reached, respectively, by the following error estimation:

$$
\begin{aligned}
\text { Error } \%= & {\left[1-\left(\frac{T_{\text {wall numerical }}}{T_{\text {wall experimental }}}\right)_{\text {Stagnation point }}\right] } \\
& \times 100
\end{aligned}
$$

The reasons for the deviation of numerical data from experimental results are discussed briefly in the following. The semi-empirical formulation for nucleation site density proposed by Lemmert and Chawla used in this research is utilized with water as the working fluid [26]. However, PF-5060 liquid in the validation is a dielectric

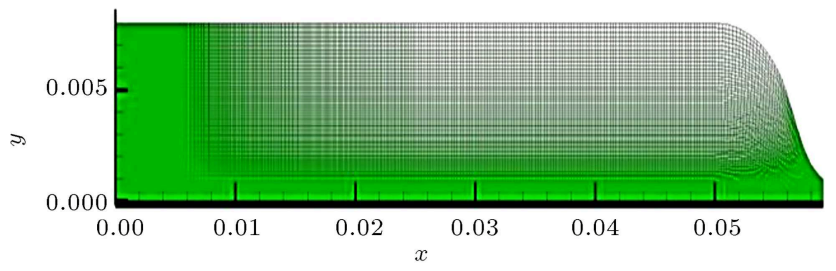

Figure 5. Meshing and computational domain of the configuration considered for validation.

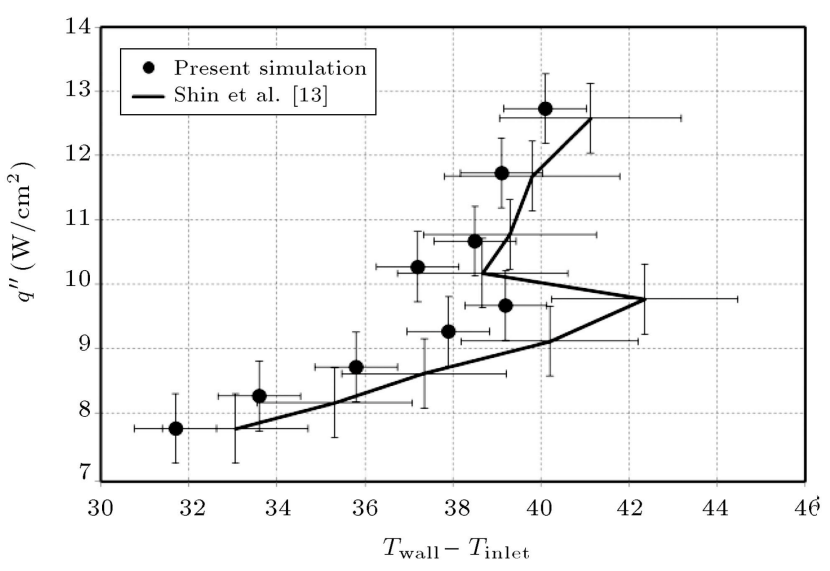

Figure 6. Validation of the numerical simulation by the experimental study of Shin et al. [13]. 
fluid. As dielectric fluids have significantly higher amounts of wetting, some nucleation sites become deactivated. As superheat increases, these nucleation sites become activated again, which is observed as the overshoot phenomenon in the boiling curve [38]. Surface tension massively increases as bubbles become smaller. This situation occurs in jet impingement boiling due to high turbulence intensities and momentum transport, which result in smaller departure diameters than those in pool boiling. Bubbles with high surface tension maintain their spherical shape. This analysis confirms that the model chosen for the lift force in the formulation of Moraga et al. is based on spherical shape for the dispersed phase [33]. However, as the average surface tension is considered in the numerical model, occurrence of a slight error is inevitable. Each of the empirical-analytical formulations in the simulation of boiling phenomenon, such as bubble departure frequency and diameter, is valid for certain ranges of wall superheat, Reynolds number, etc. and they cannot be used with the same confidence in various conditions. As it is not possible to obtain an individual correlation for each parameter in each test run, slight error to some degree is inevitable. In addition to errors regarding two-phase flow, turbulence modeling by Reynolds-Averaged Navier-Stokes (RANS) equations and Boussinesq approximation results in inaccuracies. As it has been stated in many researches, accurate prediction of turbulent flow and heat transfer has a noticeable importance in achieving reliable results. It should be noted that Direct Numerical Simulation (DNS) of this problem is not still affordable by today's computational capabilities as hundreds of particles should be analyzed individually [39].

Minimum secondary phase (vapor) thickness of $60 \mu \mathrm{m}$ in stagnation region and maximum thickness of $80 \mu \mathrm{m}$ in wall region are observed in Figure 7 . This which total heat flux of various Reynolds numbers is shown for the first $10 \mathrm{~mm}$ analysis of the vapor volume fraction along the wall is only available in the numerical studies, which complement the experimental research.

\subsection{Effect of jet Reynolds number}

The effect of jet Reynolds number based on hydraulic diameter on the rate of heat removal from target surface and the thermo-hydrodynamics of two-phase flow are studied. Fully developed velocity profile is employed for the nozzle outlet. Three Reynolds numbers of 2500, 5000, and 10000 are investigated in this configuration. Constant temperature boundary condition and fixed standoff distance of $8 \mathrm{~mm}(H / D=$ 4) from the plate are used. The range of superheat is from -5 to $16.5 \mathrm{~K}$. The inlet temperature of water is approximately $353 \mathrm{~K}$ with zero volume fraction of vapor. Comparison of the boiling curves based on the area-weighted average total heat flux can be seen in Figure 8.

According to the extracted results, the rate of heat transfer between heated plate and the impinging

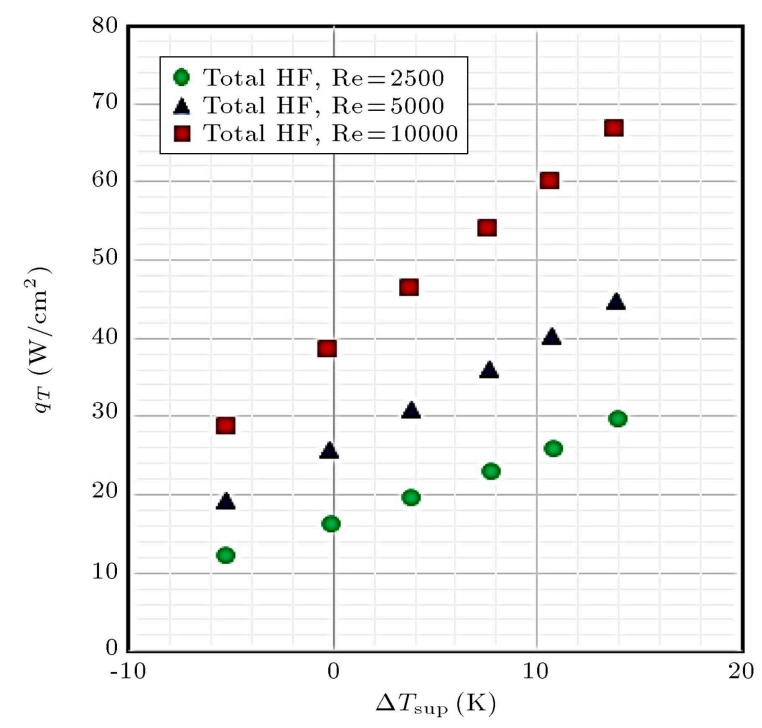

Figure 8. Total heat flux for various jet Reynolds numbers based on nozzle hydraulic diameter.

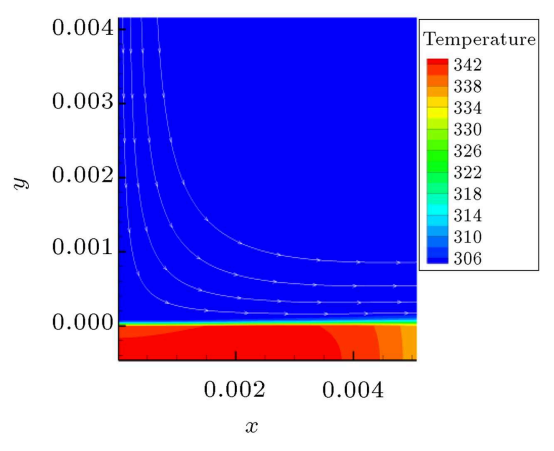

(a)

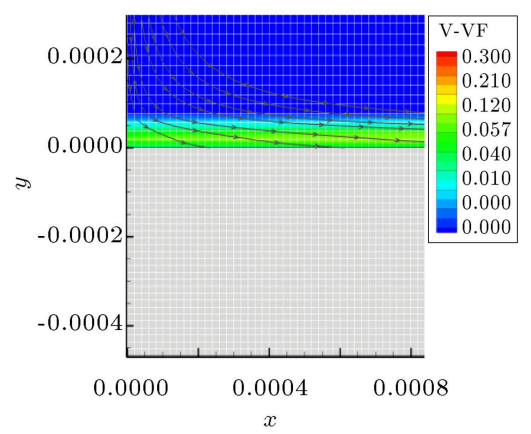

(b)

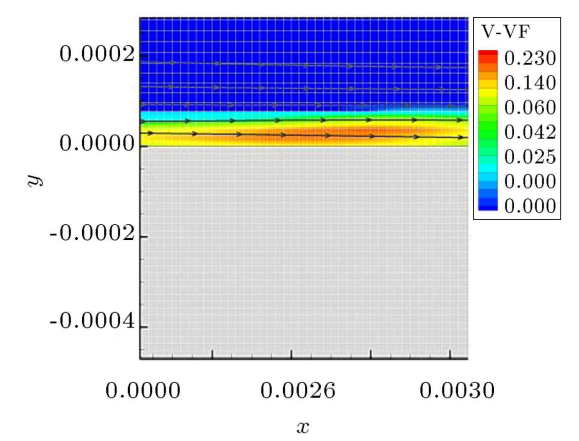

(c)

Figure 7. (a) Temperature contour with streamlines. (b) Vapor volume fraction contours with streamlines at stagnation region. (c) Wall region of the numerical validation at stagnation point temperature of approximately $341 \mathrm{~K}$. 


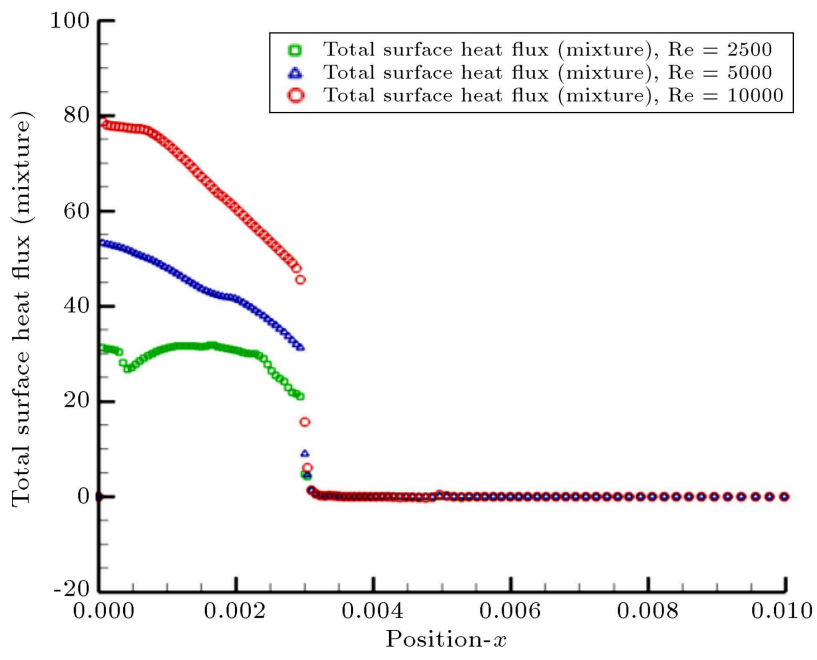

Figure 9. Total heat flux $\left(\mathrm{W} / \mathrm{cm}^{2}\right)$ from the stagnation point to the first $10 \mathrm{~mm}$ along the surface at temperature of approximately $387 \mathrm{~K}$.

jet improves noticeably as jet velocity increases. Jet Reynolds of 10000 has the highest rate of cooling and jet Reynolds of 2500 has the lowest rate, as predicted. This conclusion can also be seen in Figure 9, in of surface from the stagnation point.

As shown in Figure 9, at the center of the impinging jet, the stagnation point has the highest rate of cooling (maximum heat removal) and by getting away from position zero, the rate of heat transfer decreases along $x$-direction. By reaching the $3 \mathrm{rd} \mathrm{mm}$, the junction plate is polycarbonate with almost zero heat transfer.

Temperature and volume fraction distributions for different Reynolds numbers are displayed in Figure 10. Based on the temperature curve, the temperatures of the copper surface with the three Reynolds numbers are approximately equal with constant temperature boundary condition. However, Reynolds 2500 shows $1 \mathrm{~K}$ higher surface temperature on stagnation point than Reynolds 10000 does, which verifies the stated analysis of the jet boiling thermohydrodynamics. On the right part of Figure 10, it is observed that by increasing jet velocity, rate of heat transfer increases. As a result, flow velocity increases on the wall, which results in lower bubble growth time, and a lower number of bubbles have the opportunity to collide and form larger bubbles. This forced convection leads to smaller bubble departure diameters and higher condensation, which results in decrease in vapor volume fraction on the copper plate. This trend changes after the $3 \mathrm{rd} \mathrm{mm}$ due to jet hydrodynamics at polycarbonate junction. The reason for this issue is described in Figure 11.

As jet Reynolds increases, the momentum boundary layer becomes thinner; as a result, the flow pushes the vapor towards the wall. An extra velocity increase

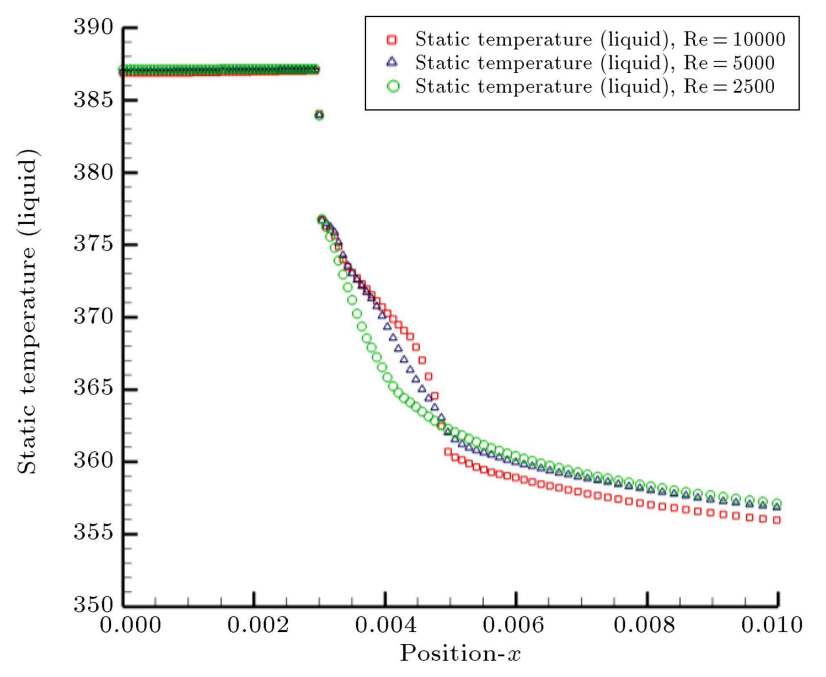

(a)

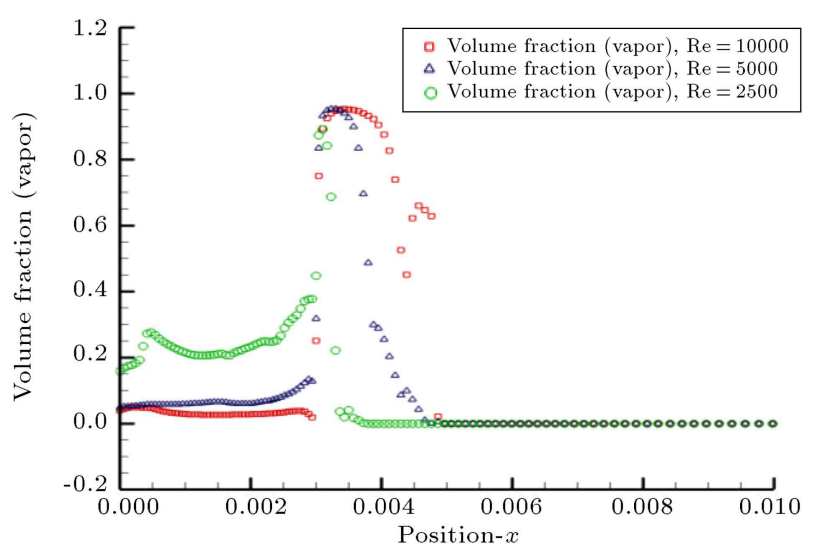

(b)

Figure 10. (a) Surface temperature in Kelvin. (b) Vapor volume fraction from the stagnation point to the first $10 \mathrm{~mm}$ along the plate direction at constant temperature of approximately $387 \mathrm{~K}$.

also appears in the wall region due to impingement jet physics. The peak in the fourth millimeter of vapor volume fraction occurs because of this phenomenon.

Secondary phase thickness at various Reynolds numbers is shown in Figure 11. As can be seen, Reynolds numbers of 2500 and 10000 represent maximum and minimum values of thickness, respectively. Noticeable separation of flow is observed in the wall region according to the given streamlines. These are called secondary vortices, which are associated with pressure gradient fluctuations based on Zuckerman and Lior explanation [36]. Secondary peak raises local turbulence intensity in the flow, which leads to increase in heat and mass transfer rates. However, overall flow kinetic energy decreases downstream due to this phenomenon.

\subsection{Effect of $\boldsymbol{H} / \mathrm{D}$}

Ratio of the nozzle distance from target surface to 

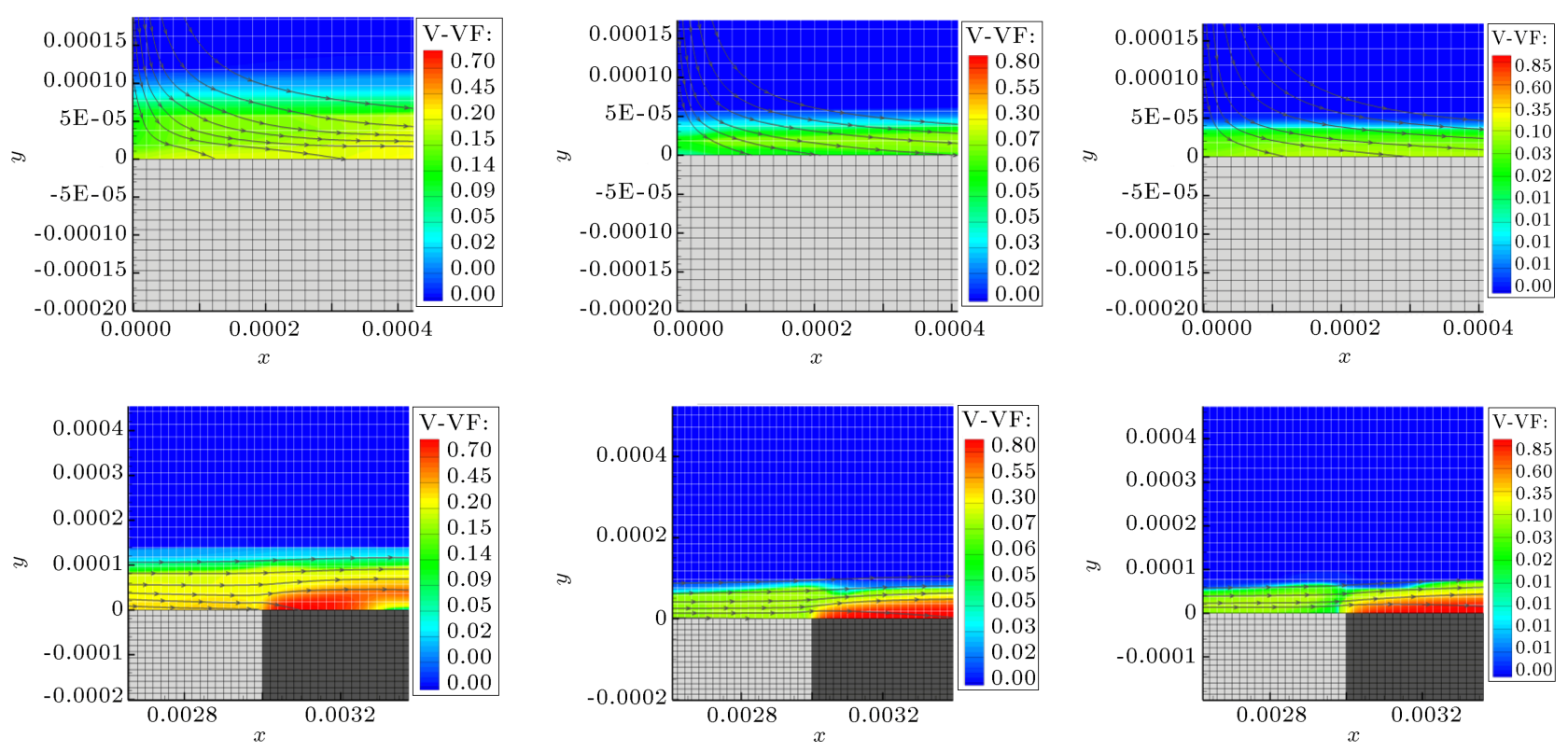

Figure 11. Vapor volume fraction contours at stagnation region (fist row) and wall region (second row) at constant temperature of $387 \mathrm{~K}$ at jet Reynolds numbers from left to right: 2500, 5000, and 10000 .

nozzle hydraulic diameter is considered an important parameter in jet impingement studies. The effect of standoff distance is investigated at $H / D$ ratios of 2 , 4 , and 6 in this research. This study is conducted at fixed Reynolds number of 5000 and, like in the previous parametric study, fully developed velocity profile is employed at nozzle exit. The employed configuration in terms of materials, dimensions of target surface, and insulation is same as that in the jet Reynolds number study. A comparison of the boiling curves based on the area-weighted average total heat flux is shown in Figure 12.

By reviewing boiling curves in terms of the $H / D$ parameter, it can be seen that with decrease in nozzle to target surface distance, the amount of total heat transfer increases. Thus, $H / D=2$ has the highest rate of cooling and $H / D=6$ has the minimum rate. This concept is displayed in Figure 13 by total heat flux from stagnation point to $10 \mathrm{~mm}$ distance along the plate.

A trend analogous to that in the Reynolds study for surface temperature and vapor volume fraction is observable with various $H / D$ ratios, as shown in Figure 14.

As it can be seen on the left, as $H / D$ increases, the rate of cooling decreases, which results in escalation of surface temperature on the copper plate. Temperature difference of $0.7 \mathrm{~K}$ is found at stagnation point. On the left, vapor volume fraction along the surface is lower at the smallest $H / D$ than at higher $H / D$ ratios, which are 4 and 6 . This is explained by velocity contours in Figure 15.

As $H / D$ ratio decreases, the length of potential

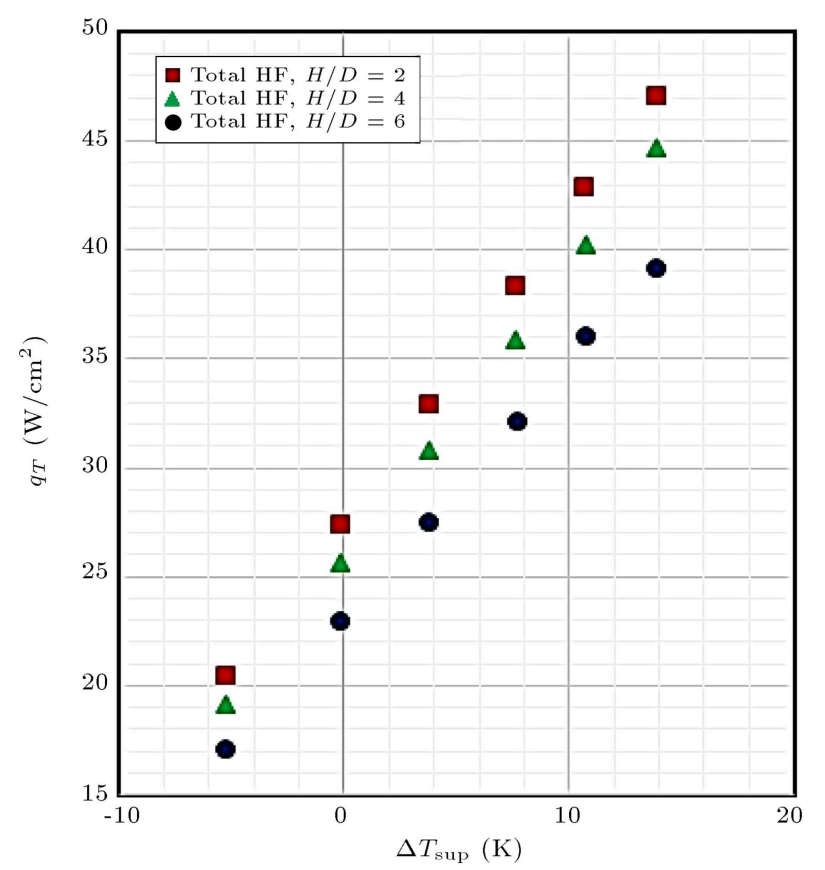

Figure 12. Total heat flux for various distances of jet nozzle from target surface.

core shortens, which results in positive flow acceleration of the wall and eventually higher rate of cooling. Table 2 summarizes secondary phase thickness values at stagnation point and junction (3rd $\mathrm{mm}$ ) for Reynolds and $H / D$ studies.

\section{Conclusion}

A solution was proposed in order to simulate turbulent 


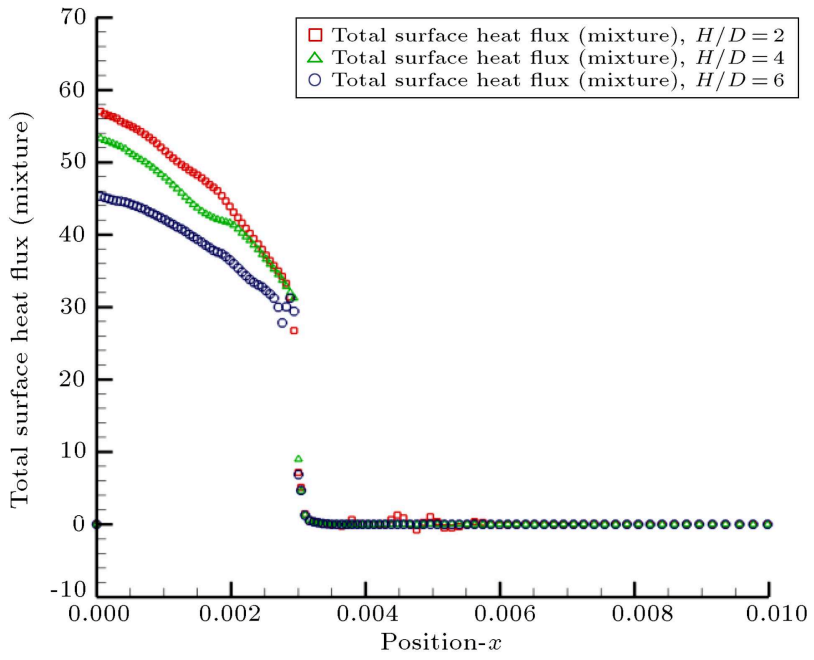

Figure 13. Total heat flux $\left(\mathrm{W} / \mathrm{cm}^{2}\right)$ from the stagnation point to the first $10 \mathrm{~mm}$ along the surface at temperature of approximately $387 \mathrm{~K}$.
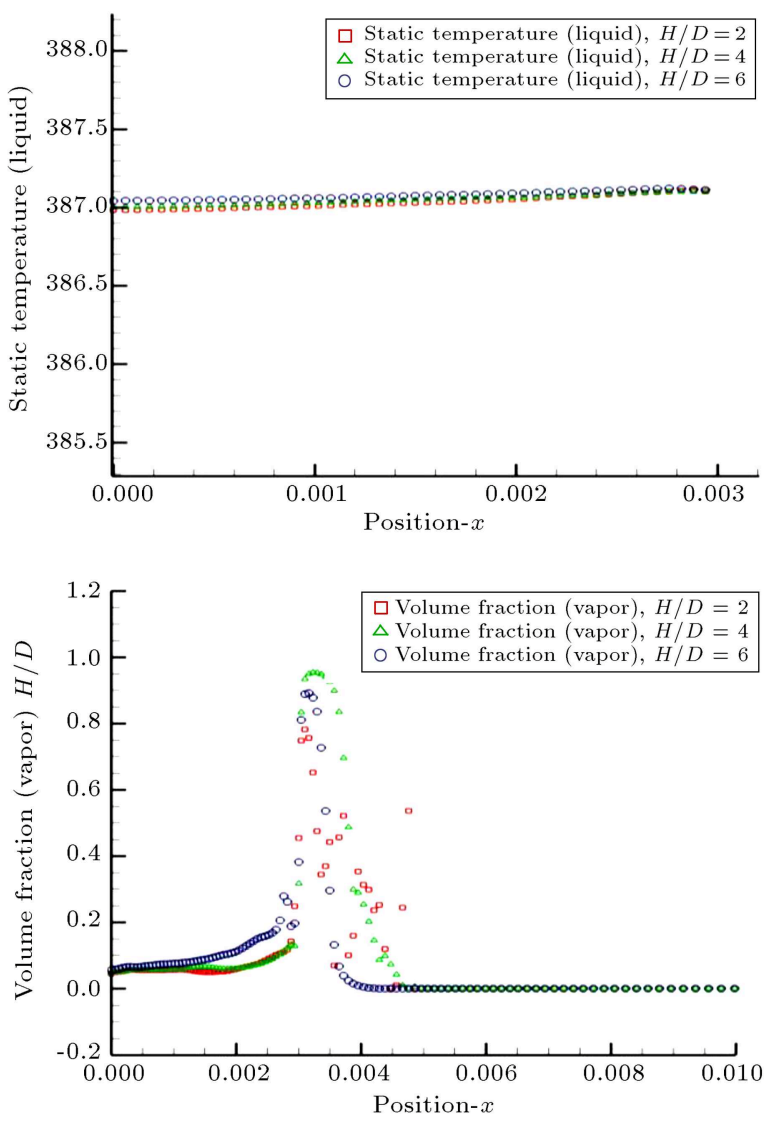

Figure 14. (a) Surface temperature on the copper plate in Kelvin. (b) Vapor volume fraction from the stagnation point along the plate direction at constant temperature of approximately $387 \mathrm{~K}$.

jet impingement subcooled boiling flow in the confined configuration by employing Eulerian multiphase model. RPI wall boiling model and RNG $k-\varepsilon$ turbulence model were utilized by considering appropriate in-
Table 2. Comparison of the dispersed phase (vapor) thicknesses on the target surface.

\begin{tabular}{ccc}
\hline & $\begin{array}{c}\text { Stagnation } \\
\text { point }\end{array}$ & $\begin{array}{c}\text { Junction } \\
\text { (3rd mm } \\
\text { from center) }\end{array}$ \\
\hline Reynolds 2500 & $96 \mu \mathrm{m}$ & $140 \mu \mathrm{m}$ \\
Reynolds 5000 & $52 \mu \mathrm{m}$ & $103 \mu \mathrm{m}$ \\
Reynolds 10000 & $41 \mu \mathrm{m}$ & $72 \mu \mathrm{m}$ \\
$H / D 2$ & $48 \mu \mathrm{m}$ & $90 \mu \mathrm{m}$ \\
$H / D 4$ & $52 \mu \mathrm{m}$ & $103 \mu \mathrm{m}$ \\
$H / D 6$ & $59 \mu \mathrm{m}$ & $105 \mu \mathrm{m}$ \\
\hline
\end{tabular}

terfacial terms for the problem. Validation of the numerical framework was carried out by utilizing the experimental study of Shin et al. Minimum error of $4 \%$ and maximum deviation of $15 \%$ were observed at stagnation point. The effect of jet Reynolds number based on hydraulic diameter ( $\operatorname{Re} 2500,5000$, and 10000) and nozzle standoff distance from target surface $(H / D 2,4$, and 6$)$ was discussed and analyzed in detail. Various existing and novel graphs and contours were provided in order to deepen the current perception of this issue. Our studies indicated that by increasing jet Reynolds number and decreasing standoff distance, total rate of cooling would increase on the target surface and vice versa. Total heat flux curves coupled with thermo-hydrodynamic illustrations confirmed the reported conclusions. As the numerical simulation of jet impingement with phase change has been addressed only recently by researchers due to its high volume of complexity in physics and great number of involved parameters, further investigation into this area is still necessary. The current research attempted to investigate the main variables and introduced new methods of reporting results, which would play a key role in jet impingement subcooled boiling studies.

\section{Acknowledgements}

This research was financially supported by the ViceChancellery for Research and Technology of Islamic Azad University, Damavand Branch.

\section{Nomenclature}

$\begin{array}{ll}p & \text { Continues phase }(-) \\ q & \text { Dispersed phase }(-) \\ \rho & \text { Density }\left(\mathrm{kg} / \mathrm{m}^{3}\right) \\ K & \text { Thermal conductivity }(\mathrm{W} / \mathrm{m}-\mathrm{K}) \\ C_{P} & \text { Specific heat }(\mathrm{J} / \mathrm{kg}-\mathrm{K}) \\ \mu & \text { Viscosity }(\mathrm{kg} / \mathrm{m} . \mathrm{s})\end{array}$



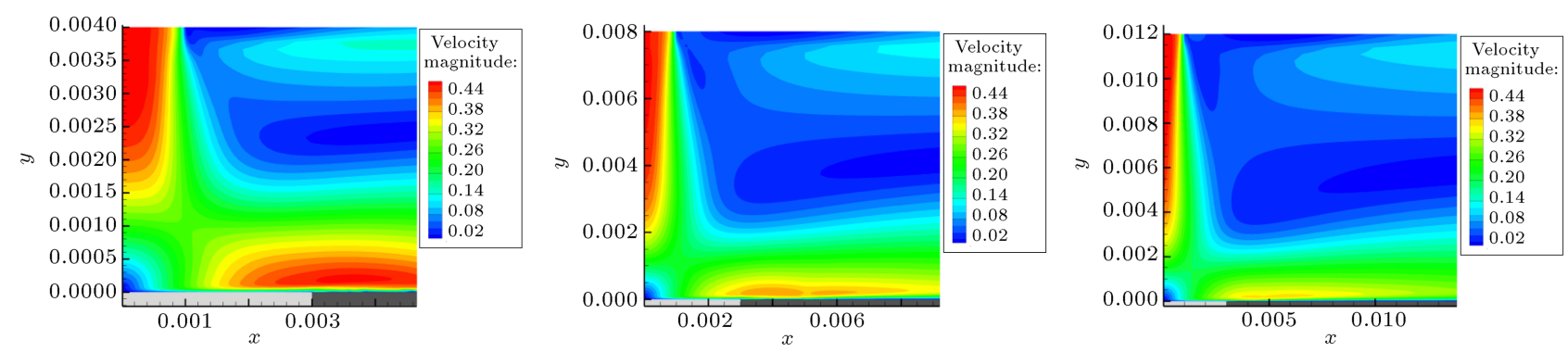

Figure 15. Liquid velocity contours at constant temperature of $387 \mathrm{~K}$ with $H / D$ ratios from left to right: 2,4 , and 6 .

\begin{tabular}{|c|c|}
\hline$\sigma$ & Surface tension $(\mathrm{N} / \mathrm{m})$ \\
\hline$L$ & Latent heat $(\mathrm{J} / \mathrm{kg})$ \\
\hline$h_{c}$ & Convective HT coefficient $(\mathrm{J} / \mathrm{kg})$ \\
\hline$T$ & Temperature $(\mathrm{K})$ \\
\hline$w$ & Wall (-) \\
\hline$l$ & Liquid phase (-) \\
\hline$v$ & Vapor phase (-) \\
\hline$T_{\text {sat }}$ & Saturation temperature (K) \\
\hline$\Delta T_{\text {sup }}$ & Wall superheat $(\mathrm{K})$ \\
\hline$\lambda$ & Diffusivity $\left(\mathrm{m}^{2} / \mathrm{s}\right)$ \\
\hline$V_{d}$ & Volume of bubble $\left(\mathrm{m}^{3}\right)$ \\
\hline$T$ & Periodic time (s) \\
\hline$h_{f v}$ & Latent heat of vaporization $(\mathrm{J} / \mathrm{kg})$ \\
\hline$N_{w}$ & Nucleation site density $\left(\mathrm{m}^{-2}\right)$ \\
\hline$f$ & Bubble departure frequency $\left(\mathrm{s}^{-1}\right)$ \\
\hline$\Delta T_{\text {sub }}$ & Degree of subcooling (K) \\
\hline$U$ & Velocity $(\mathrm{m} / \mathrm{s})$ \\
\hline$D_{w}$ & Bubble departure diameter (m) \\
\hline$d_{b}$ & Bubble diameter (m) \\
\hline$\alpha$ & Volume fraction (-) \\
\hline$A$ & Area $\left(\mathrm{m}^{2}\right)$ \\
\hline$C_{D}$ & Drag coefficient (-) \\
\hline$C_{l}$ & Lift coefficient (-) \\
\hline $\operatorname{Re}$ & Reynolds number (-) \\
\hline$C_{q p}$ & Interphase exchange coefficient (-) \\
\hline$v_{t q}$ & Kinematic eddy viscosity $\left(\mathrm{m}^{2} / \mathrm{s}\right)$ \\
\hline$\sigma_{T D}$ & Turbulent dispersion Prandtl (-) \\
\hline$F_{\text {disp }}$ & Turbulent dispersion force $(\mathrm{N} / \mathrm{m})$ \\
\hline$y^{+}$ & $y$-plus $(-)$ \\
\hline$q_{C}$ & Convective heat flux $(\mathrm{J} / \mathrm{s})$ \\
\hline$q_{Q}$ & Quenching heat flux $(\mathrm{J} / \mathrm{s})$ \\
\hline$q_{E}$ & Evaporative heat flux $(\mathrm{J} / \mathrm{s})$ \\
\hline$q_{T}$ & Total heat flux $(\mathrm{J} / \mathrm{s})$ \\
\hline $\mathrm{Ja}$ & Jakob number (-) \\
\hline
\end{tabular}

\section{References}

1. Rivallin, J. and Viannay, S. "General principles of controlled water cooling for metallurgical on-line hot rolling processes: forced flow and sprayed surfaces with film boiling regime and rewetting phenomena", International Journal of Thermal Science, 40, pp. 263272 (2001).

2. Robidou, H., Auracher, H., Gardin, P., Lebouche, M., and Bogdanic, L. "Local heat transfer from a hot plate to a water jet", Heat and Mass Transfer, 39, pp. 861867 (2003).

3. Shinaya, T., Tomofumi, H., Yuichi, M., Suhaimi, B.I., Aloke, K.M., Koutaro, T., and Masanori, M. "Characteristics of transient heat transfer and wetting phenomena during laminar jet quenching on rotating cylinder", 6th BSME Int. Conf. on Thermal Engineering, Dhaka, Bangladesh, pp. 787-797 (2015).

4. Timm, W., Weinzierl, K., and Leipertz, A. "Heat transfer in subcooled jet impingement boiling at high wall temperatures", International Journal of Heat and Mass Transfer, 46, pp. 1385-1393 (2003).

5. Rau, M.J. and Garimella, S.V. "Local two-phase heat transfer from arrays of confined and submerged impinging jets", International Journal of Heat and Mass Transfer, 67, pp. 487-498 (2013).

6. Karwa, N. "Experimental study of water jet impingement cooling of hot steel plates", Ph.D. Thesis, Technical University Darmstadt, Germany (2012).

7. Klausner, J.F., Mei, R., Bernhard, D.M., and Zeng, L.Z. "Vapor bubble departure in forced convection boiling", International Journal of Heat and Mass Transfer, 36(3), pp. 651-662 (1993).

8. Kandlikar, S.G., Cartwright, M.D., and Mizo, V.R. "Investigation of bubble departure mechanism in subcooled flow boiling of water using high-speed photography", Int. Conf. on Convective Flow Boiling, Alberta, Canada, pp. 161-166 (1995).

9. Mitsutake, Y. and Monde, M. "Heat transfer during transient cooling of high temperature surface with an impinging jet", International Journal of Heat and Mass Transfer, 37, pp. 321-328 (2001).

10. Robidou, H., Auracher, H.H., Gardin, P., and Lebouch, M. "Controlled cooling of a hot plate with a water jet", Experimental Thermal Sciences, 26, pp. 123-129 (2002). 
11. Omar, A.M.T. "Experimental study and modeling of nucleate boiling during free planar liquid jet impingement", Ph.D. Thesis, McMaster University, Canada (2010).

12. Omar, A.M.T., Hamed, M.S., and Shoukri, M. "Modeling of nucleate boiling heat transfer under an impinging free jet", International Journal of Heat and Mass Transfer, 52, pp. 5557-5566 (2009).

13. Shin, C.H., Kim, K.M., Lim, S.H., and Cho, H.H. "Influences of nozzle-plate spacing on boiling heat transfer of confined planar dielectric liquid impinging jet", International Journal of Heat and Mass Transfer, 52, pp. 5293-5301 (2009).

14. Narumanchi, S., Troshko, A., Bharathan, D., and Hassani, V. "Numerical simulations of nucleate boiling in impinging jets: Applications in power electronics cooling", International Journal of Heat and Mass Transfer, 51, pp. 1-12 (2008).

15. Abishek, S., Narayanaswamy, R., and Narayanan, V. "Suitability evaluation of bubble departure diameter and frequency models for the simulation of subcooled confined jet impingement boiling", Proceedings of the ASME, 4th Joint US-European Fluids Engineering Division Summer Meeting (2014).

16. Shademan, M. "CFD simulation of impinging jet flows and boiling heat transfer", Ph.D. Dissertation, Mechanical Engineering Dept., University of Windsor, Windsor, Ontario, Canada (2015).

17. Qui, L., Dubey, S., Choo, F.H., and Duan, F. "Recent developments of jet impingement nucleate boiling", International Journal of Heat and Mass Transfer, 89, pp. $42-58$ (2015).

18. Qui, L., Dubey, S., Choo, F.H., and Duan, F. "Experimental and numerical study of jet impingement boiling heat transfer on hot tube array", 14th International Conference on Nanochannels, Microchannels, and Minichannels, Washington, DC, USA (2016).

19. ANSYS Fluent 16.0. Theory guide, ANSYS Inc. (2015).

20. Kurul, N. and Podowski, M.Z. "On the modeling of multidimensional effects in boiling channels", 27th National Heat Transfer Conference, Minneapolis, Minnesota, USA (1991).

21. Egorov, Y. and Menter, F. "Experimental implementation of the RPI wall boiling model in CFX-5.6", Technical Report, ANSYS/TR-04-10, ANSYS GmbH (2004).

22. Del Valle, V.H. and Kenning, D.B.R. "Subcooled flow boiling at high heat flux", International Journal of Heat and Mass Transfer, 28(10), pp. 1907-1920 (1985).

23. Cole, R. "A photographic study of pool boiling in the region of the critical heat flux", AIChE Journal, 6, pp. 533-542 (1960).

24. Podowski, R.M., Drew, D.A., Lahey, R.T.J., and Podowski, M.Z. "A mechanistic model of the ebullition cycle in forced convection subcooled boiling", 8th International Topical Meeting on Nuclear Reactor Thermal-Hydraulics, Kyoto, Japan, pp. 1535-1542 (1997).

25. Krepper, E. and Rzehak, R. "CFD for subcooled flow boiling: Simulation of DEBORA experiments", Nuclear Engineering and Design, 241, pp. 3851-3866 (2011).

26. Lemmert, M. and Chawla, L.M., Influence of Flow Velocity on Surface Boiling Heat Transfer Coefficient in Heat Transfer in Boiling, E. Hahne and U. Grigull, Eds., Academic Press and Hemisphere, New York, NY, USA (1977).

27. Unal, H.C. "Maximum bubble diameter, maximum bubble-growth time and bubble-growth rate during subcooled nucleate flow boiling of water up to $17.7 \mathrm{M}$ $\mathrm{N} / \mathrm{m}^{2} "$, International Journal of Heat and Mass Transfer, 19, pp. 643-649 (1976).

28. Tolubinski, V.I. and Kostanchuk, D.M. "Vapor bubbles growth rate and heat transfer intensity at subcooled water boiling", 4th International Heat Transfer Conference, 5, Paper no. B2.8, Paris-Versailles, France (1970).

29. Kurul, N. and Podowski, M.Z. "Multidimensional effects in forced convection subcooled boiling", 9th International Heat Transfer Conference, 1, pp. 21-26 (1990).

30. Hibiki, T. and Ishii, M. "One-group interfacial area transport of bubbly flows in vertical round tubes", International Journal of Heat and Mass Transfer, 43, pp. 2711-2726 (2000).

31. Ranz, W.E. and Marshall, W.R. "Evaporation from drops", Chemical Engineering Progress, 48(3), pp. 141-146 (1952).

32. Ishii, M. "Two-fluid model for two-phase flow", 2nd International Workshop on Two-phase Flow Fundamentals, RPI, Troy, NY, USA (1979).

33. Moraga, F.J., Bonetto, R.T., and Lahey, R.T. "Lateral forces on spheres in turbulent uniform shear flow", International Journal of Multiphase Flow, 25, pp. 1321-1372 (1999).

34. Burns, A.D., Frank, T.H., Hamill, I., and Shi, J.M. "The Favre averaged drag model for turbulent dispersion in Eulerian multi-phase flows", Fifth International Conference on Multiphase Flow, Yokohama, Japan (2004).

35. Hosseinalipour, S.M., Esmailpour, K., Yahyaee, A., and Mujumdar, A.S. "Numerical simulation of flow and thermal characteristics of harmonic pulsed laminar impinging streams", Asia-Pacific Journal of Chemical Engineering, 8(4), pp. 607-617 (2013).

36. Zuckerman, N. and Lior, N. "Impingement heat transfer: Correlations and numerical modeling", Transactions of the ASME, 127, pp. 565-631 (2005).

37. Troshko, A.A. and Hassan, Y.A. "A two-equation turbulence model of turbulent bubbly flow", International Journal of Multiphase Flow, 22(11), pp. 1965-2000 (2001). 
38. Hwang, G.J. "Transport phenomena in thermal control: Cooling technologies for electronic equipment \& rotating machinery", International Symposia on Transport Phenomena, CRC Press (1989).

39. Nourgaliev, R., Knoll, D., Mousseau, V., and Berry, R. "Direct numerical simulation of boiling multiphase flows: State-of-the-art, modeling, algorithmic and computer needs", Joint International Topical Meeting on Mathematics \& Computation and Supercomputing in Nuclear Applications, American Nuclear Society, Monterey, California, LaGrange Park (2007).

\section{Biographies}

Kazem Esmailpour is Assistant Professor of Thermo-fluid Engineering at Islamic Azad University of Damavand Branch, Iran. He obtained a $\mathrm{PhD}$ in Mechanical Engineering from Iran University of Science and Technology (IUST) in 2014. He has carried out researches on single-phase and two-phase impinging and opposing jet contactors, thermal system optimization, and heat transfer enhancement. He is a fellow of the Research Center of Energy, Water and Environment at IUST, Tehran, Iran.
Arad Azizi is $\mathrm{PhD}$ student in the Department of Mechanical Engineering at State University of New York in Binghamton, NY, USA. This paper is based on his MSc thesis research (2014-16) in the Mechanical Engineering Department of Iran University of Science and Technology. He has carried out various researches regarding forced convective cooling, thermal analysis, and solar energy conversion systems. His research interests are microscale heat and mass transport, multiphase flows, and sustainability.

Seyed Mostafa Hosseinalipour is Associate Professor in the Department of Mechanical Engineering and the Head of Aerospace Group at Iran University of Science and Technology, Tehran, Iran. He is also director of the Research Center of Energy, Water and Environment as well as the Office of Sustainability at IUST. He obtained his PhD from the Department of Mechanical Engineering at McGill University, Montreal, Canada, in 1996. His main research areas are optimization and design of energy consuming and energy conversion systems, CFD and parallel processing, impinging jets, and drying. 